\title{
Pericardite em suínos ao abate no Rio Grande Sul: avaliação de agentes bacterianos e lesões associadas ${ }^{1}$
}

\author{
Carolini F. Coelho ${ }^{2}$, Priscila Zlotowski ${ }^{3}$, Caroline P. de Andrade ${ }^{3}$, Sandra \\ M. Borowski ${ }^{4}$, Thaís S. Gaggini ${ }^{2}$, Laura L. de Almeida ${ }^{4}$, David Driemeier ${ }^{3}$ \\ e David E.S.N. de Barcellos ${ }^{2 *}$
}

\begin{abstract}
Coelho C.F., Zlotowski P., Andrade C.P., Borowski S.M, Gaggini T.S., Almeida L.L., Driemeier D. \& Barcellos D.E.S.N. 2014. [Bacterial agents and lesions associated with pericarditis in slaughter pigs in Rio Grande do Sul, Brazil.] Pericardite em suínos ao abate no Rio Grande Sul: avaliação de agentes bacterianos e lesões associadas. Pesquisa Veterinária Brasileira 34(7):643-648. Setor de Suínos, Faculdade de Veterinária, Universidade Federal do Rio Grande do Sul, Av. Bento Gonçalves 9090, Porto Alegre, RS 91540-000, Brazil. E-mail: davidbarcellos@terra.com.br

The objective of the study was to identify the frequency of macroscopic and microscopic lesions and bacterial agents involved with pericarditis in slaughter pigs in the State of Rio Grande do Sul, Brazil. The samples were collected in slaughterhouses with Federal Inspection Service (SIF) between February and October, 2010. Condemnation due to pericarditis in the examined animals was 3.9\% $(299 / 7,571)$. Ninety one cases of pericarditis were examined and by histopathology $89 \%$ were chronic and $47 \%$ of the corresponding lungs showed chronic pleuritis, but there was no significant association between both lesions. The bacterial agents isolated from the hearts were Streptococcus spp., Pasteurella multocida, Haemophilus parasuis and Streptococcus suis. Bacterial DNA from Mycoplasma hyopneumoniae and Actinobacillus pleuropneumoniae were the most frequently detected by PCR. There was significant association between isolation of $P$. multocida and Streptococcus spp. in the hearts and corresponding lungs. The results suggest that lung infection could act as a port of entry to the colonization of the adjacent pericardium. In spite of the fact that M. hyopneumoniae was the agent more frequently identified by PCR in the heart and corresponding lung, there was no significant association of the agent in the organs. This suggests that the infections were independent events. The other agents investigated did not show significant association between isolation or DNA detection in heart and corresponding lungs. Another important finding was the presence of coinfection between bacterial agents in $2 \%$ of the hearts and by PCR were identified bacterial DNA of two or more agents in $16.5 \%$ of the hearts. These results suggest that coinfections in cases of pericarditis need further investigation.

INDEX TERMS: Pericarditis, swine, Pasteurella, Streptococcus, Mycoplasma hyopneumoniae.
\end{abstract}

RESUMO.- 0 objetivo do presente estudo foi identificar a frequência de lesões macroscópicas e microscópicas e dos agentes bacterianos envolvidos em pericardites em suínos

\footnotetext{
${ }^{1}$ Recebido em 15 de outubro de 2013.

Aceito para publicação em 4 de junho de 2014.

${ }^{2}$ Setor de Suínos, Faculdade de Veterinária (Favet), Universidade Federal do Rio Grande do Sul (UFRGS), Avenida Bento Gonçalves 9090, Porto Alegre, RS 91540-000, Brasil.*Autor para correspondência: davidbarcellos@ terra.com.br

${ }^{3}$ Setor de Patologia Veterinária, Favet-UFRGS, Porto Alegre, RS.

${ }^{4}$ Instituto de Pesquisas Veterinárias Desidério Finamor (IPVDF), Estrada do Conde 6000, Eldorado do Sul, RS 92990-000, Brasil.
}

no abate no Estado do Rio Grande do Sul. As amostras foram coletadas em frigoríficos de suínos com Serviço de Inspeção Federal (SIF) entre fevereiro a outubro de 2010 e a condenação por pericardite dos animais acompanhados foi de 3,9\% (299/7.571). No total foram investigados 91 casos de pericardites, $89 \%$ deles foram classificados como crônicos por histopatologia e pleurite crônica foi observada em $47 \%$ dos pulmões correspondentes, todavia não houve associação significativa entre as duas lesões. Os agentes bacterianos isolados a partir dos corações foram Streptococcus spp., Pasteurella multocida, Haemophilus parasuis e Streptococcus suis. DNA bacterianos mais detectados pela 
PCR foram de Mycoplasma hyopneumoniae e Actinobacillus pleuropneumoniae. Houve associação significativa entre isolamento de P. multocida e Streptococcus sp. nos corações e pulmões correspondentes. Esses resultados sugerem que a infecção no pulmão possa ter servido de porta de entrada para a colonização do pericárdio adjacente. Apesar de $M$. hyopneumoniae ter sido o agente detectado com maior frequência pela PCR em corações e pulmões correspondentes, não houve associação significativa da detecção dos agentes nos órgãos. Isto sugere que as infecções foram eventos independentes. Os demais agentes investigados não apresentaram associação significativa entre isolamento ou detecção de DNA em coração e pulmão correspondente. Outro achado importante foi a presença de coinfecções bacterianas em $2 \%$ dos corações e por PCR foi detectado DNA bacteriano de dois ou mais agentes em $16,5 \%$ dos corações. Esses resultados sugerem que as coinfecções em pericardites precisam ser melhor estudadas.

TERMOS DE INDEXAÇÃO: Pericardite, suínos, Pasteurella, Streptococcus, Mycoplasma hyopneumoniae.

\section{INTRODUÇÃO}

As pericardites constituem importante causa de condenações em frigoríficos e determinam perdas no processamento das carcaças e nas exportações. Processos inflamatórios em pericárdio suíno são frequentemente de origem bacteriana (Sciarrone et al. 2007) e Actinobacillus pleuropneumoniae, Actinomyces pyogenes, Haemophilus parasuis, Mycoplasma hyopneumoniae, Mycoplasma hyorhinis, Pasteurella multocida e Streptococcus suis são os agentes mais encontrados (Buttenschon et al. 1997). A lesão resulta predominantemente de infecção disseminada por via hematógena e faz parte de quadros específicos como doença de Glässer, mas também pode ter origem de permeação linfática de processo inflamatório em tecido adjacente, como o pulmão (Maxie \& Robinson, 2007). Como existe proximidade anatômica entre pulmão e coração, é possível que processos infecciosos possam afetar por contiguidade estas vísceras.

Algumas doenças ou lesões em suínos são difíceis de serem detectadas clinicamente nas fases finais da terminação por serem crônicas ou subclínicas. Lesões como pleurites e pericardites são usualmente diagnosticadas apenas no exame de inspeção visual ao abate (Buttenschon et al. 1997). Assim, a monitoria de abate é uma importante fonte de dados na avaliação da condição sanitária das granjas, que apoia o diagnóstico de manifestações clínicas e subclínicas em animais na fase de terminação e na quantificação da gravidade de lesões (Sorensen et al. 2006). A detecção dos agentes envolvidos e a caracterização macroscópica e microscópica das lesões produzidas por eles têm grande importância para o diagnóstico e adoção de práticas de manejo e controle mais eficientes (Fablet et al. 2012).

Na Dinamarca, a prevalência de pericardite fibrinosa em suínos abatidos foi de aproximadamente $0,02 \%$, com condenação anual de cerca de 3.500-4.000 carcaças na população estudada (Buttenschon et al. 1997). No Brasil, as informações sobre a prevalência e agentes envolvidos nas pericardites ou a relação existente entre pericardite e lesões pulmonares ou pleurais são escassas (Santos et al. 2010).

0 presente trabalho avaliou a frequência de pericardites em suínos no abate em frigoríficos do Estado do Rio Grande do Sul e identificou os agentes bacterianos envolvidos, utilizando histopatologia, bacteriologia e PCR.

\section{MATERIAL E MÉTODOS}

Coleta de amostras. As amostras foram coletadas em quatro frigoríficos de diferentes empresas integradoras do estado do Rio Grande do Sul das regiões do Vale do Taquari e Serra que contavam com Serviço de Inspeção Federal (SIF). Durante o período de fevereiro a outubro de 2010 foram realizadas oito visitas e foi acompanhado o abate de 7.571 suínos nestas ocasiões. A amostragem consistiu da coleta de corações com alterações macroscópicas no pericárdio, até alcançar 15 amostras por dia de abate. As pericardites foram classificadas conforme características morfológicas como: fibrinosa (exsudação de fibrina na cavidade pericárdica, aderência entre o pericárdio e o epicárdio), serosa (exsudato na cavidade pericárdica, sem aderências), sero-fibrinosa (pequena quantidade de líquido sero-fibrinoso e aderências entre pericárdio e epicárdio), adaptadas da classificação de Van Vleet \& Ferrans (2007). Foram também coletadas amostras dos pulmões correspondentes dos animais com lesões de pericardite e foram avaliadas as carcaças quanto à presença de aderências na cavidade torácica.

As vísceras foram colocadas em sacos plásticos individuais, identificadas e conservadas em caixas isotérmicas com gelo para transporte ao laboratório. Foram excluídos os corações cortados acidentalmente no procedimento de evisceração pela possível ruptura do pericárdio e risco de contaminação. Foram também excluídas as amostras de coração em que não foi possível coletar o pulmão correspondente para análise e processamento.

Avaliação microbiológica. Corações e pulmões colhidos foram mantidos refrigerados na temperatura de 4 a $8^{\circ} \mathrm{C}$ e no processamento foram usadas bandejas, facas, luvas, tesouras e pinças estéreis. Foi realizada a flambagem da superfície dos corações e pulmões pela cauterização da superfície com estilete aquecido. No coração, com tesoura e pinça, realizou-se um pequeno orifício entre as lâminas do pericárdio para a introdução de suabe estéril com posterior semeadura por esgotamento em placas de ágar sangue e Mac Conkey. No pulmão, fez-se um corte com bisturi na área flambada e impressão da placa com a superfície de corte do órgão. Para isolamento de bactérias como Actinobacillus pleuropneumoniae, A. suis e Haemophilus parasuis foi utilizada uma estria de Staphylococcus aureus como fonte liberadora de fator V (NAD). A leitura das placas dos isolamentos bacterianos foi realizada após $24-48$ horas de incubação a $37^{\circ} \mathrm{C}$; as colônias que apresentavam crescimento significativo foram repicadas para obtenção de cultivo puro em caldo cérebro-coração (BHI, DIFCO). A identificação dos agentes bacterianos isolados foi realizada pela verificação de características coloniais e morfotintoriais, testes bioquímicos e outras características fenotípicas conforme sugerido por Barrow \& Feltham (1993). Para a classificação de Pasteurella multocida nos tipos $\mathrm{A}$ e $\mathrm{D}$ foram usadas respectivamente às técnicas de hialuronidase (Carter \& Rundell, 1975) e acriflavina (Carter \& Subronto 1973).

Avaliação molecular. A detecção de DNA bacteriano foi realizada por reação em cadeia da polimerase (PCR) a partir de suabe das vísceras estudadas. Após a separação do pulmão e coração, com auxílio de tesoura e pinça estéril realizou-se um pequeno orifício entre as lâminas do pericárdio para a introdução de suabe 
estéril e coleta de material. No pulmão, fez-se um corte com bisturi na área flambada e introduziu-se suabe no brônquio, na região da bifurcação da traqueia. Os suabes colhidos das vísceras foram armazenados em tubos de microcentrifugação de polipropileno, próprios para análises moleculares, e posteriormente foram armazenados à $-20^{\circ} \mathrm{C}$ até o processamento.

A extração do DNA total dos suabes das vísceras foi realizada utilizando kit comercial (QiAmp DNA MINIKIT, Qiagen) de acordo com as instruções do fabricante. As amostras de DNA foram eluídas em $100 \mu \mathrm{L}$ de água ultrapura e armazenadas a $-20^{\circ} \mathrm{C}$ até a reação de polimerase em cadeia (PCR). Foram usadas PCR previamente descritas para amplificação de fragmento do gene da toxina Apx IV de A. pleuropneumoniae (Schaller et al. 2001), para o gene 16S rRNA da P. multocida (Townsend et al. 2001), para o gene $16 \mathrm{~S}$ rRNA de $H$. parasuis (Oliveira et al. 2001), para o gene 16S rRNA de M. hyopneumoniae (Yamaguti et al. 2008) e para o gene $16 \mathrm{~S}$ rRNA de M. hyorhinis (Stakenborg et al. 2006). Foram consideradas positivas para os agentes as amostras que amplificaram fragmentos dos genes estudados. Adicionalmente, produtos de amplificação das amostras de campo com tamanho esperado identificados na eletroforese de um representante de cada patógeno investigado foram confirmados com sequenciamento.

Histologia. 0 material coletado para histopatologia foi fixado em solução de formalina a $10 \%$ por um período máximo de 72 horas. Foram realizados cortes transversais dos fragmentos de coração e pericárdio; nos pulmões foi selecionada área de transição onde foi observada lesão macroscópica juntamente com área não afetada do parênquima pulmonar. As amostras foram processadas pelas técnicas de rotina histológica e emblocadas em parafina. Os cortes histológicos foram realizados em micrótomo manual a 5 micras e coradas pela técnica de hematoxilina e eosina (Prophet et al. 1992).

Análise estatística. Os resultados dos testes foram organizados em planilha eletrônica EXCEL 2010 (Microsoft USA). As associações entre as variáveis analisadas foram avaliadas por teste do Qui-quadrado $\left(\mathrm{X}^{2}\right)(\mathrm{p}<0,05)$ em programa Stata 12.0 (Stata Corp, USA).

\section{RESULTADOS}

\section{Análise macroscópica}

A condenação geral por pericardite dos animais abatidos nos dias das visitas foi de 3,9\% (299/7.571). 0 percentual de condenações por pericardite variou de 1,5\% a 8,5\%, dependendo do dia e frigorífico amostrado.

No exame macroscópico dos casos estudados $(n=91)$ a pericardite fibrinosa foi predominante com 86,8\% (79/91) em relação à pericardite serosa 9,9\% e sero-fibrinosa 3,3\%. Nos casos de pericardite fibrinosa observou-se aderência de pleura em 83,5\% (66/79) dos casos e consolidação do parênquima em 41,8\% (33/79) dos pulmões avaliados. Nos casos em que havia pericardite serosa os principais achados foram aderência da pleura ao pericárdio em $100 \%$ (9/9) e áreas de consolidação do parênquima pulmonar em $77,8 \%$ (7/9). Nos casos de pericardite sero-fibrinosa, aderência de pleura e consolidação pulmonar concomitante foi observada em 100\% (3/3)dos casos.

\section{Análise microscópica}

A principal lesão histológica observada em 86,8\% (79/91) dos corações analisados foi presença tecido de granulação, caracterizado por proliferação de tecido con- juntivo na superfície epicárdica e proliferação de vasos sanguíneos entre as camadas do tecido de granulação, o que evidencia processos crônicos. Em 6,6\% (6/91) das amostras foi encontrada camada de fibrina recobrindo o tecido de granulação e em 5,5\% (5/91) infiltrado inflamatório. Em dois casos foram observadas alterações discretas no miocárdio que consistiam em fibrose intersticial superficial, predominantemente ao redor de arteríolas com degeneração e necrose focal dos cardiomiócitos. Em 4,4\% (4/91) dos corações analisados não foi encontrada alteração microscópica.

A análise dos pulmões identificou pleurite crônica em $47,2 \%$ (43/91) dos casos e não foram observadas alterações em 26,4\% (24/91) dos pulmões analisados. Apesar de serem predominantes os processos crônicos no coração e pulmão, não apresentaram associação significativa $(p=0,196)$.

\section{Bacteriologia}

A partir dos corações foram isolados Pasteurella multocida (6,6\%), Streptococcus spp. (6,6\%), Haemophilus parasuis $(4,4 \%)$ e Streptococcus suis 1,1\% (Quadro 1). Os resultados de isolamento dos agentes detectados simultaneamente no coração e pulmão são apresentados no Quadro 1. Em 83,5\% (76/91) dos corações não houve isolamento bacteriano. Todas as amostras de P. multocida isoladas $(n=35)$ foram classificadas no tipo A. Foi encontrada associação significativa nos isolamentos do agente no coração com pericardite e o pulmão correspondente para $P$. multocida e Streptococcus spp. (Quadro 1).

\section{Biologia molecular}

A partir dos suabes dos pericárdios foram detectados por PCRs genomas de Mycoplasma hyopneumoniae (36,3\%), Actinobacillus pleuropneumoniae (19,8\%), H. parasuis (5,5\%) P. multocida (4,4\%) e Mycoplasma hyorhinis $(3,3 \%)$ (Quadro 2$)$. Foi possível amplificar DNA bacteriano simultaneamente no coração e pulmão, mas não houve associação significativa entre a detecção de nenhum dos agentes bacterianos investigados nos casos estudados (Quadro 2).

Não foram detectados DNA bacterianos em 47,3\% (43/91) dos corações estudados. Em 15,4\% (14/91) das amostras de coração foi observada a presença de mais de um agente (Quadro 3).

Quadro 1. Isolamento bacteriano em 91 corações de suínos com pericardites coletados em abatedouro no RS em 2010

\begin{tabular}{lcccccc}
\hline \multicolumn{1}{c}{ Agentes isolados } & \multicolumn{2}{c}{$\begin{array}{c}\text { Animais com } \\
\text { pericardite }(\mathrm{n}=91)\end{array}$} & & \multicolumn{2}{c}{$\begin{array}{c}\text { Isolamento em coração e } \\
\text { pulmão correspondente }\end{array}$} \\
\cline { 2 - 3 } \cline { 5 - 6 } & Coração & Pulmão & & Frequência & Valor de p* \\
\cline { 1 - 4 } Streptococcus spp. & 6 & 16 & & 4 & 0,008 \\
Pasteurella multocida & 6 & 13 & & 4 & 0,003 \\
Haemophilus parasuis & 4 & 2 & & 1 & 0,086 \\
Streptococcus suis & 1 & 4 & & 0 & N.A. \\
Actinobacillus & 0 & 1 & & 0 & N.A.
\end{tabular}

pleuropneumoniae

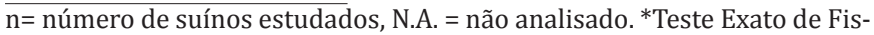
cher. 
Quadro 2. Frequência absoluta de detecção de DNA de agentes bacterianos em 91 corações de suínos com pericardite coletados em abatedouro no RS em 2010

\begin{tabular}{|c|c|c|c|}
\hline \multirow[t]{2}{*}{ Agentes isolados } & \multicolumn{2}{|c|}{$\begin{array}{c}\text { Animais com } \\
\text { pericardite }(n=91)\end{array}$} & \multirow{2}{*}{$\begin{array}{l}\text { Coração e pulmão } \\
\text { correspondente* } \\
\text { Frequência }\end{array}$} \\
\hline & Coração & Pulmão & \\
\hline Mycoplasma hyopneumoniae & 33 & 78 & 30 \\
\hline $\begin{array}{l}\text { Actinobacillus } \\
\text { pleuropneumoniae }\end{array}$ & 18 & 36 & 10 \\
\hline Haemophilus parasuis & 5 & 39 & 4 \\
\hline Pasteurella multocida & 4 & 31 & 4 \\
\hline Mycoplasma hyorhinis & 3 & 11 & 1 \\
\hline
\end{tabular}

* Não houve associação significativa no Teste Quiquadro e Teste Exato de Fischer, valores de $\mathrm{p}>0,05$.

Quadro 3. Co-infecções identificadas por detecção de DNA de agentes bacterianos em 91 corações de suínos com pericardite coletados em abatedouro no RS em 2010

\begin{tabular}{|c|c|c|}
\hline $\begin{array}{l}\text { Codetecções de DNA de } \\
\text { bactérias nos corações }\end{array}$ & $\begin{array}{c}\text { Freq. } \\
\text { absoluta }\end{array}$ & $\begin{array}{l}\text { Freq. } \\
\text { relativa }\end{array}$ \\
\hline $\begin{array}{l}\text { Mycoplasma hyopneumoniae }+ \\
\text { Actinobacillus pleuropneumoniae }\end{array}$ & 7 & $7,7 \%$ \\
\hline $\begin{array}{l}\text { Mycoplasma hyopneumoniae + } \\
\text { Pasteurella multocida }\end{array}$ & 3 & $3,3 \%$ \\
\hline $\begin{array}{l}\text { Mycoplasma hyorhinis }+ \\
\text { Haemophilus parasuis }\end{array}$ & 2 & $2,2 \%$ \\
\hline $\begin{array}{l}\text { Mycoplasma hyopneumoniae + } \\
\text { Haemophilus parasuis }\end{array}$ & 1 & $1,1 \%$ \\
\hline $\begin{array}{l}\text { Mycoplasma hyopneumoniae + Actinobacillus } \\
\text { pleuropneumoniae + Pasteurella multocida }\end{array}$ & 1 & $1,1 \%$ \\
\hline
\end{tabular}

\section{DISCUSSÃO}

A condenação por pericardite de 3,9\% nos abates acompanhados ( $\mathrm{n}=7571$ carcaças) foi próxima aos valores encontrados na Síria por Schuh et al. (1998) no abate de 6.250 suínos, sendo encontrado um percentual de 2,6\% de pericardites. Variações nos índices de condenação podem ter relação com o estado de saúde dos rebanhos, onde valores menores geralmente são encontrados em rebanhos livres de patógenos (Buttenschon et al. 1997). No presente estudo, o percentual de condenações por pericardite variou de $1,5 \%$ a $8,5 \%$, dependendo do dia e do frigorífico amostrado. É reconhecido que há grande variação entre diferentes lotes de leitões terminados em relação a problemas de origem infecciosa monitoráveis no abate, como consolidações pulmonares, pleurites e pericardites. Isto pode ser um reflexo das condições multifatoriais capazes de interferir com a ocorrência e gravidade de doenças infecciosas a campo como desafios ambientais, problemas de manejo, falhas em programas vacinais e de medicação (Sorensen et al. 2006). Também deve ser considerada a eventual presença de agentes imunodepressores e facilitadores de pneumonias e pleurites como circovírus suíno tipo 2 (PCV-2), vírus da influenza e micotoxinas. 0 papel destes agentes em casos de pericardite é de difícil avaliação (Osweiler 2006) e não eram o foco do presente estudo.

A pericardite fibrinosa foi o tipo predominante, observada em 86,8\% (79/91). Inicia como processo inflamatório agudo com presença de fibrina no saco pericárdio, podendo haver exsudato purulento e/ou hemorrágico. Com a evolução da lesão ocorre a organização do exsudato e aderên- cia à superfície serosa, tornando-a espessada, opaca e sem brilho (Maxie \& Robinson, 2007). Alterações semelhantes podem estar presentes na superfície pulmonar adjacente, por esse motivo, um pulmão afetado poderia representar uma importante via de disseminação de patógenos para o pericárdio contíguo. No entanto, essa hipótese não pode ser confirmada no presente estudo, uma vez que não houve associação estatística significativa entre as lesões crônicas encontradas nos pericárdios e nas pleuras analisadas. Pneumonias e pleurites em suínos são mais comuns na fase inicial da terminação e por isso, ao abate, as lesões encontradas são geralmente crônicas (Sorensen et al. 2006). Este argumento poderia também ser aplicado a pericardites, e assim poderia explicar a alta frequência de pericardite fibrinosa, característica da forma crônica, observada no atual estudo. 0 exame bacteriológico das pleuras foi negativo em 83,5\% dos casos (76/91). Em apenas 12,1\% (11/91) dos casos havia fibrina e/ou infiltrado inflamatório e não houve detecção bacteriana em seis, confirmando a cronicidade dos casos de pericardite analisados.

Foi possível isolar Pasteurella multocida em seis amostras de coração e em 13 amostras de pulmão correspondente. Foi observada associação significativa entre os isolamentos nas vísceras estudadas (Quadro 1). Diferente disso, a PCR permitiu detectar maior número de vísceras com DNA de P. multocida (Quadro 2), mas não foi possível comprovar associação significativa entre as detecções no coração e pulmão correspondentes estudados. Todas as amostras identificadas por PCR do pericárdio e pulmão pertenciam ao tipo capsular A. Concordando com estes resultados, no Brasil, Santos et al. (2010) isolaram predominantemente $P$. multocida tipo A de casos de pericardite em suínos de 20 a 106 dias de idade. Existem poucas referências adicionais de detecção de $P$. multocida associada à pericardite em suínos, como o registro nos Estados Unidos de Pijoan \& Fuentes (1987), que isolaram P. multocida A em dois surtos naturais de doença respiratória severa de animais com pericardite e pleurite. 0 tipo de Pasteurella mais frequentemente isolado de lesões pneumônicas e de pleura é o A, embora o D possa eventualmente ser encontrado (Pijoan 2006). Recentemente, vem aumentando a associação de cepas do tipo D com pleurite e pneumonia em suínos no Brasil e em outros países. Analisando materiais provenientes do Estado de Santa Catarina, Mores (2006) avaliou 162 pulmões de suínos abatidos e rejeitados por lesões de pneumonia e pleurite e encontrou $24 \%$ das amostras de P. multocida do tipo A e 27,3\% de bactérias do tipo D.

Em seis corações e em 16 pulmões correspondentes houve isolamento de Streptococcus spp. e houve associação significativa entre os isolamentos das vísceras dos casos de pericardites investigados $(p=0,008)$ (Quadro 1). Esses resultados sugerem que a infecção no pulmão possa ter servido de porta de entrada para a colonização do pericárdio adjacente. As cepas de Streptococcus spp. deste estudo foram avaliadas fenotipicamente, com base em características coloniais e provas bioquímicas. Entretanto, apenas 1,1\% (1/91) dos isolados de coração e 4,4\% (4/91) de pulmão foram classificados como $S$. suis, que é a espécie de Strepto- 
coccus spp. geralmente envolvida em casos de pericardite (Pagnani et al. 2002).

Em somente 4,4\% (4/91) das amostras de coração e em $2.2 \%(2 / 91)$ dos pulmões foi isolado Haemophilus parasuis. Não foi possível comprovar associação significativa $(p=0,086)$ entre os isolamentos do coração e pulmão correspondente nos casos estudados (Quadro 1). Houve detecção de DNA de $H$. parasuis em 5,5\% (5/91) no coração e em $42,9 \%$ (39/91) das amostras de pulmão e não foi possível confirmar associação significativa entre as detecções nas vísceras estudadas (Quadro 2). 0 agente é fastidioso e morre com facilidade após a abertura das placas no laboratório, dificultando após o seu isolamento o subcultivo e identificação bioquímica. Por isso, a detecção de DNA bacteriano por PCR, que independe da viabilidade bacteriana, é considerada mais sensível (Oliveira 2004), o que pode explicar o maior número de detecções de $H$. parasuis pela PCR. Aqui também deve ser considerado que a doença tende a ocorrer nas fases de creche e iniciais na terminação, por isso no abate a maioria das infecções já estará resolvida, restando apenas DNA detectável pela PCR (Santos et al. 2012). É muito importante considerar que deve ser tomado cuidado na interpretação de resultados de bacteriologia ou PCR de amostras coletadas de sítios como cavidade nasal, traqueia ou mesmo tecido pulmonar, pois nestes locais $H$. parasuis pode ser encontrado como comensal (Pijoan \& Oliveira, 2002).

A detecção do DNA de Mycoplasma hyopneumoniae correspondeu ao maior número de resultados positivos pela PCR tanto no coração $36,3 \%$ (33/91) como no pulmão 85,7\% (78/91) (Quadro 2). Apesar de ser o agente mais frequentemente detectado nos órgãos estudados, não foi possível confirmar associação significativa entre a presença de DNA bacteriano no coração e no pulmão correspondente. M. hyopneumoniae é considerado patógeno com tropismo para os cílios da traqueia, brônquios e bronquíolos e não parece estabelecer infecções sistêmicas (Thacker 2006); apesar desse patógeno já ter sido isolado em casos de pericardite fibrinosa em suínos de abate (Buttenschon et al. 1997). $O$ significado biológico da detecção de DNA de $M$. hyopneumoniae em casos de pericardite como encontrado no relato atual e em outros (Buttenschon et al. 1997) precisa ser melhor esclarecido. Estudos moleculares que permitam a quantificação do agente e caracterização das cepas bacterianas envolvidas poderão auxiliar na elucidação do papel de Mycoplasma nas pericardites. Outra questão a ser elucidada é se a infecção pulmonar e de outros sítios (como o pericárdio) se dá com a mesma cepa bacteriana ou com cepas diferentes. Estudos mais recentes identificaram variação de cepas de $M$. hyopneumoniae encontradas em pulmão, suabe de traqueia e lavado bronquial (Vranckx et al. 2011) e ainda não foi determinado se existem ou não diferenças genotípicas entre as cepas de M. hyopneumoniae presentes no pulmão e no pericárdio.

Houve detecção de Actinobacillus pleuropneumoniae em 19,8\% (18/91) dos corações e em 39,6\% (36/91) dos pulmões pela PCR (Quadro2). No entanto, na bacteriologia, o agente não foi isolado de nenhuma amostra de coração (Quadro 1). Esse resultado, ao abate, pode ser explicado porque a doença tende a ocorrer nas fases iniciais de aloja- mento na terminação e por esse motivo a maioria das infecções já estará resolvida na fase final da terminação, restando apenas DNA detectável na PCR (Gottschalk et al. 2003).

Foi detectado Mycoplasma hyorhinis em três amostras de coração (3,3\%) e em 11 amostras de pulmão $(12,1 \%)$. Vale ressaltar que não houve associação significativa entre detecção de genoma bacteriano nos corações e pulmões correspondentes dos casos de pericardite estudados (Quadro 2). Infecções com outros patógenos respiratórios são comuns em casos de polisserosite associada com M. hyorhinis; por sua vez H. parasuis é um agente que frequentemente aparece em associação com este agente (Rovira et al. 2010). No presente estudo, H. parasuis foi encontrado em duas amostras de coração positivas para $M$. hyorhinis (Quadro 3). Todavia o papel de M. hyorhinis nos casos de pericardite, ao abate, precisa ser melhor definido.

Por isolamento bacteriano, foram identificadas apenas 2 coinfecções nos 91 casos de pericardite estudados (Streptococcus spp. com H. parasuis e Streptococcus spp. com $P$. multocida). Já por detecção de DNA foi possível identificar 5 tipos de coinfecções distintas envolvendo 16,5 \% (15/91) dos corações suínos com pericardite analisados (Quadro 3 ). Esses resultados podem ser explicados por uma possível permanência de DNA bacteriano após resolução de infecção. No trabalho de Santos et al. (2010) sobre agentes bacterianos de pericardites ocorreram coinfecções em $3,1 \%$ das amostras analisadas envolvendo A. pleuropneumoniae, P. multocida A e D, H. parasuis e S. suis. Possíveis explicações para o maior percentual de coinfecções presentes no trabalho atual em comparação com o de Santos et al. (2010) é o fato de que naquele foi usada exclusivamente a bacteriologia para detecção dos agentes e não foi analisado M. hyopneumoniae. De maneira geral, são comuns as associações entre patógenos em doenças respiratórias de suínos (Mores 2011), mas são escassas as análises de associações em casos de pericardite em suínos de abate.

\section{CONCLUSÕES}

Os casos de pericardite investigados foram caracterizados predominantemente como lesões crônicas. Os agentes bacterianos mais isolados foram Pasteurella multocida e Streptococcus spp.

0 agente mais frequentemente encontrado por detecção de genoma bacteriano nos corações estudados foi Mycoplasma hyopneumoniae.

Foi possível comprovar associação significativa entre isolamento de P. multocida e Streptococcus spp. no coração e no pulmão correspondente dos casos de pericardites estudados.

Os demais agentes investigados não apresentaram associação significativa entre detecção nas vísceras (coração e pulmão). Ocorreram coinfecções bacterianas nos casos analisados, sugerindo que a importância dessas interações causando pericardites precisa ser melhor estudada.

Agradecimentos.- À Coordenação de Aperfeiçoamento de Pessoal de nível Superior (CAPES) pela concessão da bolsa de Pós-Doutorado da segunda autora e auxílio financeiro (PNPD - processo $\mathrm{n}^{\circ}$ 02641/09-7) e ao Conselho Nacional de Desenvolvimento Científico e Tecnológico (CNPq) pelo auxílio financeiro durante execução deste trabalho. 


\section{REFERÊNCIAS}

Barrow G.I. \& Feltham R.K.A. 1993. Cowan and Steel's Manual for the Identification of Medical Bacteria. $3^{\text {rd }}$ ed. Cambridge University Press, New York. 352p.

Buttenschon J., Friis N.F., Aalbaek B., Jensen T.K., Iburg T. \& Mousing J. 1997. Microbiology and pathology of fibrinous pericarditis in Danish slaughter pigs. Zentralbl. f. Veterinärmed. 5:271-280.

Carter G.R. \& Rundell S.W. 1975. Identification of type A strains of Pasteurella multocida using staphylococcal hyaluronidase. Vet. Rec. 87:343-343.

Carter G.R. \& Subronto P. 1973. Identification of type D strains of Pasteurella multocida with acriflavine. Am. J. Vet. Res. 34:293-294.

Fablet C., Marois C., Dorenlor V., Eono F., Eveno E., Jolly J.P., Devendec L.L., Kobisch M., Madec F. \& Rose N. 2012. Bacterial pathogens associated with lung lesions in slaughter pigs from 125 herds. Res. Vet. Sci. 93:627-630.

Gottschalk M., Broes A. \& Fittipaldi N. 2003. Recent developments on Actinobacillus pleuropneumoniae. Proc. $34^{\text {th }}$ American Association of Swine Veterinarians, Florida, p.387-393.

Maxie M.G. \& Robinson W.F. 2007. Cardiovascular system, p.1-106. In: Jubb K.V.F., Kennedy P.C. \& Palmer N. (Eds), Patology of Domestic Animals. Vol.3. $5^{\text {th }}$ ed. Saunders Elsevier, Philadelphia.

Mores M.A.Z. 2006. Anatomopatologia e microbiologia de lesões pulmonares responsáveis por condenações de carcaças em suínos. Paraná, Brasil. Dissertação de Mestrado, Universidade Federal do Paraná, Curitiba. 90p.

Mores M.A.Z., Kuchiishi S.S., Ascoli K.R. \& Mores N. 2011. Etiologia de problemas respiratórios de suínos enviados ao CEDISA para diagnóstico em 2010. Anais XV Congresso ABRAVES, Fortaleza, Brasil, Pasta E. (CD ROM)

Oliveira S. 2004. Improving rate of success in isolating Haemophilus parasuis from clinical samples. J. Swine Health Produc. 12:308-309.

Oliveira S., Galina L. \& Pijoan C. 2001. Development of a PCR test to diagnose Haemophilus parasuis infections. J. Vet. Diagn. Invest. 13:495-501.

Osweiler G.D. 2006. Occurrence of mycotoxins in grains and feeds, p.915929. In: Straw B.E., Zimmerman J.J., D’Allaire S. \& Taylor D.J. (Eds), Diseases of Swine. $9^{\text {th }}$ ed. Blackwell Publishing, Iowa.

Pagnani K.J.R., Castro A.F.P., Gottschalk M., Silveira W.S. \& Nakazato G. 2002. Sorotipagem de amostras de Streptococcus suis isoladas de suínos em granjas dos Estados de São Paulo, Minas Gerais e Paraná. Pesq. Vet. Bras. 22:1-5.

Pijoan C. \& Fuentes M. 1987. Severe pleuritis associated with certain strains of Pasteurella multocida in swine. J. Am. Vet. Med. Assoc. 191: 823-826.

Pijoan C. \& Oliveira S. 2002. Haemophilus parasuis: challenges and change. Proc. $33^{\text {rd }}$ American Association of Swine Veterinarians, Missouri, p.251253.

Pijoan C. 2006. Pneumonic pasteurellosis, p.719-726. In: Straw B.E., D`Allaire S., Mengeling W.L. \& Taylor D.J. (Eds), Diseases of Swine. $9^{\text {th }}$ ed. Blackwell Publishing, Ames.
Prophet E.B., Mills B., Arrington J.B. \& Sobin L.H. 1992. Laboratory Methods in Histotechnology. Armed Forces Institute of Pathology, Washington, DC., p.279.

Rovira A., Clavijo M.J. \& Oliveira S. 2010. Mycoplasma hyorhinis infection in pigs. Acta Scient. Vet. 38:9-15.

Santos J.L., Santos L.F., Santos D.L., Pasqualon H.P. \& Guimaraes W.V. 2010. Agents isolated in pericarditis cases from pigs in the nursery, growing and finishing in Brazil. Proc. $21^{\text {st }}$ International Pig Veterinary Society Congress, Vancouver, Canada, p.910.

Santos J.L., Sobestiansky J. \& Santos L.F. 2012. Doença de Glässer, p.135140. In: Sobestiansky J. \& Barcellos D. (Eds), Doenças dos Suínos. $2^{\underline{a}}$ ed. Cânone, Goiânia.

Schaller A., Djordjevic S.P., Eamens G.J., Forbes W.A., Kuhn R., Kuhnert P., Gottschalk M., Nicolet J. \& Frey J. 2001. Identification and detection of Actinobacillus pleuropneumoniae by PCR based on the gene apxIVA. Vet. Micol. 79:47-62.

Schuh M., Köfer J., Fuchs K., Smulders F.J.M., Resch J. \& Wiskott W. 1998. Installation of a feed-back recording system in a Syrian slaughterhouse. Proc. $15^{\text {th }}$ International Pig Veterinary Society Congress, Birmingham, p.25.

Sciarrone F., Stlla S. \& Bonardi S. 2007. Valutazione della efficacia di dissanguamento delle carcasse di suini affetti da pericardite: studio preliminare. Annali della Facoltà di Medicina Veterinaria di Parma 27:165172.

Sorensen V., Jorsal S.E. \& Mousing J. 2006. Diseases of the respiratory system, p.149-177. In: Straw B.E., Zimmerman J.J., D’Allaire S. \& Taylor D.J. (Eds), Diseases of Swine. $9^{\text {th }}$ ed. Blackwell Publishing, Iowa.

Stakenborg T., Vicca J., Butaye P., Imberechts H., Peeters J., De Kruif A., Haesebrouck F. \& Maes D. 2006. Multiplex PCR to identify porcine mycoplasmas present in broth cultures. Vet. Res. Commun. 30:239-247.

Thacker E. 2006. Mycoplasmal diseases, p.701-717. In: Straw B.E., Zimmerman J.J., D’Allaire S. \& Taylor D.J. (Eds), Diseases of Swine. $9^{\text {th }}$ ed. Blackwell Publishing, Iowa.

Townsend K.M., Boyce J.D., Chung J.Y., Frost A.J. \& Adler B. 2001. Genetic organization of Pasteurella multocida cap loci and development of a multiplex capsular PCR typing system. J. Clin. Microbiol. 39:924-929. (Erratum in: J. Clin. Microbiol. 39:2378, 2001).

Van Vleet J.F. \& Ferrans V.J. 2007. Cardiovascular system, p.575-578. In: Carlton W.W. \& MacGavin M.D. (Eds), Pathologic Basis of Veterinary Disease. $4^{\text {th }}$ ed. Elsevier, St Louis.

Vranckx K., Maes D., Calus D., Villarreal I., Pasmans F. \& Haesebrouck F. 2011. Multiple-Locus Variable-Number Tandem-Repeat Analysis is a suitable tool for differentiation of Mycoplasma hyopneumoniae strains without cultivation. J. Clin. Microbiol. 49:52020-2023.

Yamaguti M., Muller E.E., Piffer A.I., Kich J.D., Klein C.S. \& Kuchiishi S.S. 2008. Detection of Mycoplasma hyopneumoniae by Polymerase Chain Reaction in swine presenting respiratory problems. Braz. J. Microbiol. 39:471-476. 